Journal of Economics and Behavioral Studies

Vol. 5, No. 4, pp. 242-251, April 2013 (ISSN: 2220-6140)

\title{
Marketing Strategies of Herbal Cosmetic Products: Thai and Imported Products
}

\author{
Rojanadilok Thanisorn*, Nanagara Byaporn \\ School of Management, Shinawatra University, Thailand \\ *lovefirstsign@hotmail.com
}

\begin{abstract}
This research investigated the factors that influence the marketing strategies of herbal cosmetic products in Thailand by comparison between Thai and imported product where the imported products are manufactured from Australia and U.S.A. This study is both quantitative and qualitative research. The facial herbal cosmetics products in this study were moisturizer, whitening lotion, cream, power, toner, make up cleansing mask, cleansing oil, soap bar, and anti-aging lotions. Finding from the study found that the marketing strategy of Thai herbal cosmetic products have the 4Ps; Product strategy by improving the quality of products, research and development for launching the new products to the market, creating beauty packaging and new product launch attracts the market's attention. Price strategy using cash discount to increase consumer's purchase motive. Place strategy using department stores as the main distribution channels, distribution channels are direct sales with catalogs, counter sales in department store and beauty showrooms. Promotion strategy using integrated marketing communication for maintaining brand image, television advertisement, radio advertisement, cabal advertisement, booth exhibition, beauty school, website, face to face marketing and male beauty instructor to attract the women customers. Marketing strategy of imported products; Products strategies are concerned with the odor, color, physical appearance of products and the penetration characteristic of products. The strategies promote the imported products by introducing the product e.g. the product is a blend of herbs, the most effective skin care for healthy, revitalized skin and natural extract that contains active ingredients with high technology to manufacture the cosmetic product that performs a specific action to penetrate deep into the skin. The smooth odor and color of the imported products are the important purchasing decision factor. Physical appearance of products; non greasy, non oily helps absorbs quickly into skin and help smooth the skin surface texture and packaging design, color, size and shape, play a role in purchasing decisions. Packaging has to possess the strength to make eye-catching packaging that helps make the most window of opportunity in pristine conditions, brand, logo/slogan as a way to facilitate their purchasing decision; the image of the brand has all the criteria value, quality reliability trust, intangible and delivers benefits to the consumers. Price strategy is heavily differentiated due to the branding then imported herbal cosmetic products offering lower priced luxury products. The lower prices could also boost sales e.g. smaller sizes of some products, such as $50 \mathrm{ml}$ and $30 \mathrm{ml}$ bottles of products, which is normally sold in $100 \mathrm{ml}$ bottles then smaller bottles are selling better than regular size ones, Place strategy; purchasing convenience from the Internet to virtual presence e.g. Website, direct mail, social media enhancing the brand's image. The site also uses Face book page by constantly updating content photos, videos, information about events, YouTube, twitter as platforms to keep customers up to date on new episodes and development. Promotion strategies using advertisement, television advertisement
\end{abstract}

Keywords: Cosmetic, Herbal, Thai, Import, Marketing Strategy, Products, Thailand

\section{Introduction}

The marketing effort was the greater amount of marketing resources a firm invests in the development and the launch of a new product, the higher its probability of success marketing efforts for the new product accelerate the diffusion process, and speed up the adoption rate of the new product (Sun \& Hwang, 2005). Marketing personnel are constantly analyzing the patterns of buying behavior and purchase decisions. The consumption and purchase related decisions as basic purchase or consumption decisions, brand purchase or consumption decisions; channel purchase decisions and payment purchase decisions. Understanding behavior of consumers is a key to success of herbal cosmetic business organization (Jalalkamali \& Nikbin, 2010). The largest product categories in the cosmetic markets are facial moisturizers, anti-aging products, makeup foundation, lipsticks and eye makeup (New Zealand Trade and Enterprise, 2010). In addition to convenience, consumers are looking for more natural products. In Europe particularly, there has been a movement towards non oily and non greasy for 
mulations and away from mineral oil and non- greasy for mulation and away from mineral oil and petrolatum-based products to more upscale and elegant formulations. Some products even carry oil-free label on them. Many companies are planning to introduce natural vegetable-based ingredient for personal care applications. There is a move toward betahydroxy acid, polyhydroxy acids, and enzymatics for skin clarification and fine line and wrinkle removal. Other point to the demand for mildness and its key in driving buying decision among customers (Cynthia \& Arnum, 2002). Therefore, this research aims to study the marketing strategy of Thai consumers on the products between local and imported products.

\section{Literature Review}

The direct effectiveness of selling is that the product manufacturer or importer, through catalogues, broadcasting, television, that Internet, etc., transfer the product and service information to the consumer, and the consumer then replies through mail or answers through telephone emergence of network marketing (Jui et al., 2008). Marketing strategy of imported products in Thailand. Product A has the stand alone shops plus day spa and places it products in medium-high department stores. The targets customers are all genders with the ages between 30 - 50 years old, medium to high level income. The conscious of the environment and strive to source and use the most environmentally aware materials where possible. The local price strategy is discounting 10-20 percent on vocation. Product A has update promotion strategies every 6 months. Advertisement strategies focus on magazine, direct mail, brochure and social network advertisement such as face book. Product B has online shops and 12 counters in department stores located in medium-high department stores. The target customers are every genders; female, male and third gender. Product B uses Earth friendly packaging. The customers' research is an important tool for creating local marketing strategies of product B. The local price strategy is to discount occasionally. The promotion strategies focused on premium product and cash discount. The advertisement strategies have popular brand ambassador, magazine, direct mail, social network advertisement such as face book. Product $C$ concentrates the efforts and cost on the substance and quality of the products with appropriate selling prices. The product has 8 counters in medium-high department stores. Sales promotion strategies of product $\mathrm{C}$ are free premium sampling and, customers refer friends. The product has guarantee campaign (satisfaction guarantee) in 28 days or the customers can refund their purchase. The advertisement strategies focused on brochure and social network advertisement; face book and twitter (Rojanadilok, 2011). Influence of free sample usage within the luxury cosmetic market is a suggested give away to non-working housewives, as they have more time to use and promote products. Companies should also offer samples of products with a high penetration rate. It is better to choose other promotional techniques such as price reduction or advertisement. When launching a new brand, marketers should focus more on well established brand awareness by spending on advertisement before offering free samples (Amor \& Guibert, 2009). The biggest multinational cosmetics companies in the world such as Avon, Proctor and Gamble, Estee Lauder.

Nivea and L'Oreal are very much interested in the market (Ergin et al, 2005). Emerging Markets, particularly Central and Eastern Europe and China, are high on the strategic agenda of the top cosmetic/personal care companies. L'Oreal, the world's largest producer of cosmetics and personal care products, cited growth in emerging markets in Central and Eastern Europe and China when it posted a 21.8 percent increase in first half profit to €958.2 million. First half sale increased 3.6 percent to nearly $€ 7.4$ billion, with cosmetic sales up 3.8 percent to $€ 7.25$ billion. L'Oreal is scoring large gains. First half sales to Asia increased 23.3 percent to $€ 626$ million, and sales in Eastern Europe increased 28.3 percent to $€ 256$ million. Latin America sales increase 8.3 percent to $€ 344$ million. P\&G has focused on other consumer segment, one of the smallest markets by volume, with sales of only 4.0 million liters, Thailand was the next largest market with sale close to China at 24.6 million liters, and Indonesia was also very competitive. By 2007, the skin and sun care market in Asia is expected to reach volumes of 259.1 million liters, according to Data monitor. Japanese sales will reach 66.1 million liters, Chinese volume sales are expected to reach 36.1 million liters, closely follow by Indonesia with 35.1 million (rate of growth 8.3 percent), eclipsing Thailand's 5.5 percent (Arnum, 2004). Consideration of the information situation faced by members of targeted markets has the potential of providing valuable guidance in the information of marketing strategies. Depending on the extent to which an organization is targeting consumers in search, experience, or credence situations, there is a very different marketing program. The marketers face a combination of situation in different market segments. Careful research to identify the information situations faced by targeted consumers is a necessary prelude to designing effective marketing programs. 
Good research and good strategic thinking about information situations should lead to more efficient and productive marketing of all types of goods and services (Pailin \& Paul, 1995).

\section{Methodology}

Quantitative research using population is 400 women which age between $18-48$ years old who currently live in the Chonburi province. The sample size includes 10 Amphoe, and 40 women from each Amphoe (Muang, Banglamung, Sathaheap, Nongyai, Panatnikom, Banbung, Panthong, Baothong, Kaosrichang, and Sriracha). Consumers who live in Chonburi $1,172,432$ persons (female $=594,554$ persons, Male $=577,878$ persons). The sample size used cluster sampling (one- stage cluster sampling) and computed using Yamane's formula to calculate sample size. Therefore, this research collected the data from sample 400 questionnaires.

Data Collection: The questionnaire consists of three sections as follows; A first section consist of demographic data; age of respondents, occupation, highest education, job description, income, the one selection of Thai or Imported herbal cosmetic products. The second section consists of six main satisfaction of purchasing decision factors. The third section is the recommendation of the respondents. The second section consists of the 37 purchasing decision factors which covers marketing mix (4Ps). Respondents used the five point scale to rate the importance of 37 potential purchasing factors presented in the questionnaire, relating to satisfaction of purchasing factors by $1=$ strongly disagree, $2=$ disagree, $3=$ neutral, $4=$ agree, $5=$ strongly agree. To normalize the value labels scale to100 percent by input value labels $1=0.01-0.2,2=0.2-0.4,3=0.4-0.6,4=0.6-0.8,5=0.8-1.0$

\section{Results and Analysis}

Profile of respondents: Quantitative research of consumer's purchasing decision factors of Thai and imported herbal cosmetic products. A total of 480 sets of questionnaires were distributed to herbal cosmetic consumers. The respond rate was 83.33 percent. The 400 sets of questionnaires, imported product consumers were 166 people (41.5 percent) and Thai product consumers were 234 people (58.5 percent). Most of the imported herbal cosmetic respondents are aged between 21-25 years old (27.1percent). The respondents are all female. Most of respondents are private company (33.1 percent), bachelor degree (51.8 percent), monthly salary of 10,001-15,000 baths (30.1 percent). Most of the Thai herbal cosmetic respondents are aged between 21-25 years old (44.9 percent). The respondents are all female. Most of respondents are employee (21.8 percent), bachelor degree (51.8 percent), and monthly salary less than 10,000 bath (35 percent).

Reliability Analysis: The questionnaire was pilot tested on 30 respondents for reliability. The results of the pilot test showed acceptable reliability values (Cronbach's $\alpha=0.762$ ), Cronbach's $\alpha$ based on standardize item $=0.862$ and this was acceptable $\alpha$ value over the requested value of 0.70

Data Analysis: Imported herbal cosmetic products have twelve significant purchase decision factors from 37 factors; odor of product, color of product, physical appearance of product, brand, technology of product, penetration characteristic, logo /slogan, distribution channel via the Internet, price, advertisement, packaging, television advertisement. The results of the factor analysis are as shown in the table. Results show that purchase decision factors are comprised as factor with KMO (Kaiser-Meyer-Olkin Measure of sampling Adequacy) measures of sampling adequacy stood at 0.729. Thai herbal cosmetic products have twelve significant purchase decision factors from 38 factors; cash discount, service premium (face massage, make up service), product premium, advertisement, promotion activity, model, fashion magazine, purchasing convenience from department store, packaging size, technology of product, packaging design,(color/ letter style), friend, are the purchasing decision factors. The results of the factor analysis are shown in the table. Results show that purchase decision factors are comprised as factor with KMO (Kaiser-Meyer-Olkin Measure of sampling Adequacy) measures of sampling adequacy stood at 0.757

Findings of general personal data of interviewees, which purchased Imported or Thai herbal cosmetic products: The majority of interviewees of imported products are the age of 21-25 years. 
Table 1: General personal data of interviewees

\begin{tabular}{lcc}
\hline Age (Years) & Imported products (Percentage) & Thai products (Percentage) \\
\hline$<20$ & 5.4 & 5.1 \\
$21-25$ & 27.1 & 44.9 \\
$26-30$ & 22.3 & 17.9 \\
$31-35$ & 17.5 & 13.2 \\
$36-40$ & 9.6 & 4.7 \\
$41-45$ & 12.0 & 9.0 \\
$46-50$ & 6.0 & 5.1 \\
Total & 100.0 & 100.0 \\
\hline
\end{tabular}

The majority occupation of the people which the highest education was bachelor degree. The majority salary of the people were 10,001-15,000 baht per month.

Table 2: Personal data of interviewees

\begin{tabular}{llc}
\hline Personal Data & \multicolumn{1}{c}{ Imported products (Percentage) } & Thai products (Percentage) \\
\hline Occupation & & \\
Student & 24.1 & 39.3 \\
Private company & 33.1 & 28.2 \\
Government/State enterprises & 25.3 & 23.9 \\
Entrepreneur & 17.5 & 8.5 \\
Highest education & & \\
Secondary education and lower & 18.1 & 14.5 \\
Diploma & 6.6 & 4.7 \\
Bachelor & 51.8 & 64.5 \\
Master & 21.1 & 14.5 \\
Doctoral & 2.4 & 1.7 \\
Job & & \\
Casual worker & 7.2 & 6.4 \\
Employee & 21.7 & 21.8 \\
Officer & 17.5 & 16.2 \\
Head officer/Manager & 8.4 & 5.1 \\
Department manager & 3.0 & 2.1 \\
Division Manager & 4.2 & 2.6 \\
Proprietor & 15.7 & 7.3 \\
Student & 22.3 & 38.5 \\
Salary per month (baht) & & \\
$<10,000$ & 29.5 & 35.0 \\
10,001 - 15,000 & 30.1 & 29.1 \\
15,001 - 20,000 & 4.2 & 12.4 \\
20,001 - 30,000 & 18.1 & 10.3 \\
30,001 - 40,000 & 10.8 & 7.7 \\
$>40,000$ & 7.2 & 5.6 \\
\hline
\end{tabular}

The factorial design fits the research methodology which KMO (Kaiser Meyer Olkin measure of sampling adequacy) of imported product stood at 0.729 . The significant purchasing decision factors of imported herbal cosmetic explained in component factors. The Eigen values express total variances of all factors, Eigen values is sum of factor loading square and this research has 12 factors which Eigen values $>1$ (Eigen value less than 1 is useless for using that factor). The significant purchasing decision factors (Eigen values $>1$ ) explained in components factors in Table 3 and component plot in rotates space in figure 1.

Table 3: The purchasing decision factors of imported herbal cosmetic products in three components

\begin{tabular}{lcccl}
\hline Purchasing decision Factors & Component1 & Component2 & Component3 & Communality \\
\hline Odor of products & 0.742 & -0.090 & 0.104 & 0.570 \\
Color of products & 0.650 & -0.032 & -0.194 & 0.461 \\
Physical appearance of products & 0.619 & -0.200 & -0.121 & 0.438 \\
\hline
\end{tabular}




\begin{tabular}{lrlll} 
Brand & 0.604 & 0.081 & 0.156 & 0.400 \\
Technology of products & 0.550 & -0.112 & -0.121 & 0.330 \\
Penetration Characteristic & 0.525 & -0.352 & 0.127 & 0.416 \\
Logo/slogan & 0.509 & 0.321 & 0.264 & 0.432 \\
Distribution channel via internet 0.445 & -0.097 & 0.116 & 0.221 \\
Price & 0.299 & -0.249 & -0.062 & 0.155 \\
Advertisement & 0.288 & 0.674 & -0.242 & 0.596 \\
Packaging & 0.246 & 0.096 & -0.352 & 0.194 \\
Television advertisement & 0.219 & 0.130 & -0.805 & 0.723 \\
Latent root & 3.038 & 0.847 & 1.036 & 2.327 \\
Percentage of variance & 25.32 & 7.058 & 8.633 & 40.709 \\
\hline
\end{tabular}

Table 4: Paired T- Test of purchasing factors comparison Imported and Thai products at $95 \%$ confidence interval of the difference has significant of the mean 0.002

\begin{tabular}{llllllll}
\hline Mean & Std. Deviation & Std. Error Mean & Lower & Upper & t & df & Significant \\
\hline 0.459 & 0.274 & 0.104 & 0.205 & 0.712 & 4.427 & 6 & 0.002 \\
\hline
\end{tabular}

For table 3, Latent root (the sum of squares of the loading), the common factor variance for factor 1 is calculation as follow;

$(0.742)^{2}+(0.650)^{2}+(0.619)^{2}+(0.604)^{2}+(0.550)^{2}+(0.525)^{2}+(0.509)^{2}+(0.445)^{2}+$

$(0.299)^{2}+(0.288)^{2}+(0.246)^{2}+(0.219)^{2}=3.038$

For twelve variables each with a total variance of the maximum possible variance that could be extracted by any one factor is 12 , the actual variance extracted by the first factor is 3.038. A common way of expressing the latent root is to convert them to percentages of the maximum possible variance, for the first factor, the percentage variance is Latent root/Number of variances $\mathrm{x} 100$ is 3.038/12 x100 = 20.247. The percentage variances calculated for each factor are shown in the final row of table 4.3. Percentage variance expresses the contribution of the factors to the total variance. For example, percentage variance of the first three factors in analysis account for; $25.32 \%+7.058 \%+8.633 \%=40.709 \%$. The final column in table 4.3 , headed community of variable is the sum of all the common factor variance of the variable 1 , show as 0.570 is equal to the sum of:

$(0.742)^{2}+(-0.090)^{2}+(0.104)^{2}=0.570$

The percent cumulative is sum of percentage of variance of 12 factors are shown in the below table

Table 5: The percent cumulative of purchasing decision factors

\begin{tabular}{lccc}
\hline $\begin{array}{l}\text { Purchasing Decision } \\
\text { Factors }\end{array}$ & Initial Eigen values & \% of variance & \% Cumulative \\
\hline Odor of products & 7.982 & 21.006 & 21.006 \\
Color of products & 2.363 & 6.218 & 27.225 \\
Physical appearance of products & 2.050 & 5.395 & 32.620 \\
Brand & 1.886 & 4.963 & 37.583 \\
Technology of products & 1.707 & 4.492 & 42.075 \\
Penetration characteristic & 1.598 & 4.205 & 46.280 \\
Logo/slogan & 1.579 & 4.156 & 50.437 \\
Distribution channel via internet & 1.430 & 3.763 & 54.200 \\
Price of products & 1.271 & 3.344 & 57.544 \\
Advertisement & 1.187 & 3.123 & 60.666 \\
Packaging characteristic & 1.134 & 2.985 & 63.651 \\
Television advertisement & 1.062 & 2.794 & 66.446 \\
\hline
\end{tabular}


Table 6: The percent cumulative of rotation sums of squared loading of purchasing decision factors

\begin{tabular}{lccc}
\hline $\begin{array}{l}\text { Purchasing Decision } \\
\text { Factors }\end{array}$ & $\begin{array}{c}\text { Rotation sums of } \\
\text { squared loading }\end{array}$ & \% of variance & \% Cumulative \\
\hline Odor of products & 3.431 & 9.030 & 9.030 \\
Color of products & 3.216 & 8.463 & 17.492 \\
Physical appearance of products & 2.591 & 6.818 & 24.311 \\
Brand & 2.321 & 6.107 & 30.418 \\
Technology of products & 2.041 & 5.372 & 35.789 \\
Penetration characteristic & 1.992 & 5.242 & 41.031 \\
Logo/slogan & 1.806 & 4.754 & 45.784 \\
Distribution channel via internet & 1.757 & 4.623 & 50.408 \\
Price of products & 1.679 & 4.420 & 54.827 \\
Advertisement & 1.623 & 4.270 & 59.097 \\
Packaging characteristic & 1.522 & 4.006 & 63.103 \\
Television advertisement & 1.270 & 3.342 & 66.446 \\
\hline
\end{tabular}

Figure 1: Component Plot of Imported Herbal Cosmetic Products

Component Plot in Rotated Space

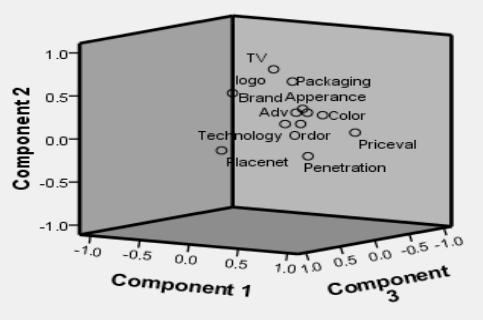

The factorial design fits in thesis methodology which KMO(Kaiser Meyer Olkin measure of sampling adequacy) of Thai products stood at 0.757 . The significant purchasing decision factors of imported herbal cosmetic explained in component factors. The eigenvalues express total variances of all factors, eigenvalues is sum of factor loading square and this research has 13 factors which eigenvalues $>1$ (eigenvalue less than 1 is useless for using that factor). The significant purchasing decision factors(eigenvalues $>1$ ) explained in components factors in Table 7 and component plot in rotates space in figure 2 .

Table 7: Purchasing decision factors of Thai herbal cosmetic products

\begin{tabular}{lllll}
\hline Purchasing decision factors & Component1 & Component2 & Component3 & Communality \\
\hline Cash discount & 0.812 & -0.060 & -0.099 & 0.673 \\
Service premium & & & & \\
(Face massage, make up) & 0.751 & -0.281 & -0.048 & 0.645 \\
Product premium & 0.670 & -0.249 & -0.175 & 0.542 \\
Advertising & 0.636 & 0.106 & -0.318 & 0.517 \\
Promotion activity & 0.620 & 0.068 & -0.207 & 0.432 \\
Model & 0.487 & -0.369 & 0.065 & 0.378 \\
Advertisement via fashion magazine & 0.419 & -0.216 & 0.047 & 0.224 \\
Distribution channel via & & & & \\
Department store & 0.341 & 0.068 & 0.480 & 0.351 \\
Packaging size & 0.302 & 0.358 & 0.372 & 0.358 \\
Technology of products & 0.175 & 0.172 & -0.147 & 0.082 \\
Packaging design (color / letter style) & 0.174 & 0.026 & 0.372 & 0.169 \\
Friends is purchasing decision factor & 0.162 & -0.278 & 0.083 & 0.110 \\
Latent root & 3.169 & 0.584 & 0.723 & 10.911 \\
Percentage of variance & 26.408 & 4.867 & 6.025 & 37.300 \\
\hline
\end{tabular}


Table 8: Paired T- Test of purchasing factors comparison between Imported and Thai products at $\mathbf{9 5 \%}$ confidence interval of the difference

\begin{tabular}{llllllll}
\hline Mean & Std. Deviation & Std. Error Mean & Lower & Upper & t & Df & Significant \\
\hline 0.446 & 0.419 & 0.187 & 0.966 & 0.074 & 2.380 & 4 & 0.038 \\
\hline
\end{tabular}

The percent cumulative of percentage of variance of 12 factors is 66.895 are shown in table

Table 9: The percent cumulative of purchasing decision factors

\begin{tabular}{lccc}
\hline Purchasing decision factors & Initial Eigen values & \% of variance & \% Cumulative \\
\hline Cash discount & 6.608 & 17.389 & 17.389 \\
Service premium & & & \\
(Face massage, make up) & 3.868 & 10.180 & 27.569 \\
Product premium & 2.441 & 6.424 & 33.993 \\
Advertising & 1.909 & 5.024 & 39.017 \\
Promotion activity & 1.704 & 4.485 & 43.502 \\
Model & 1.580 & 4.159 & 47.660 \\
Advertisement via fashion magazine & 1.531 & 4.028 & 51.688 \\
Distribution via department store & 1.301 & 3.425 & 55.113 \\
Packaging size & 1.207 & 3.177 & 58.290 \\
Technology of products & 1.143 & 3.007 & 61.297 \\
Packaging design (color/litter style) & 1.108 & 2.917 & 64.214 \\
Friend & 1.019 & 2.680 & 66.895 \\
\hline
\end{tabular}

Figure 2: Component Plots of Thai Herbal Cosmetic Products

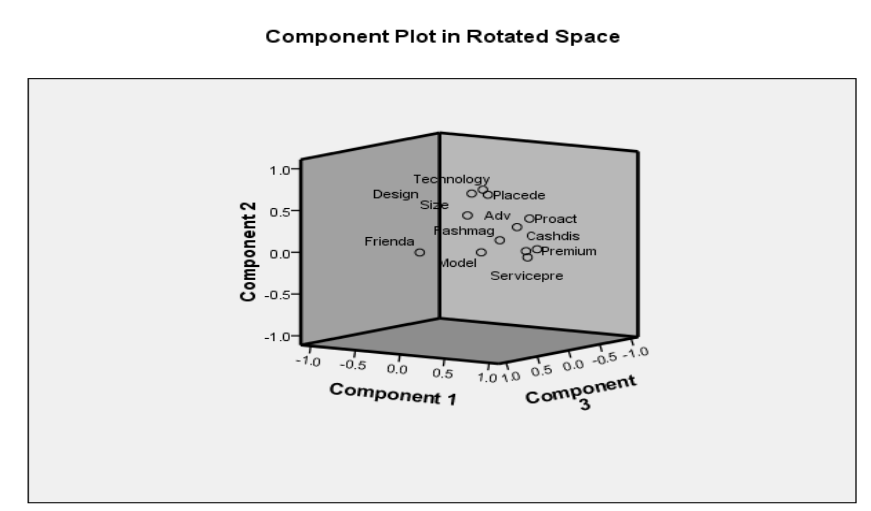

Table 10: The percent cumulative of rotation sums of squared loading of purchasing decision factors

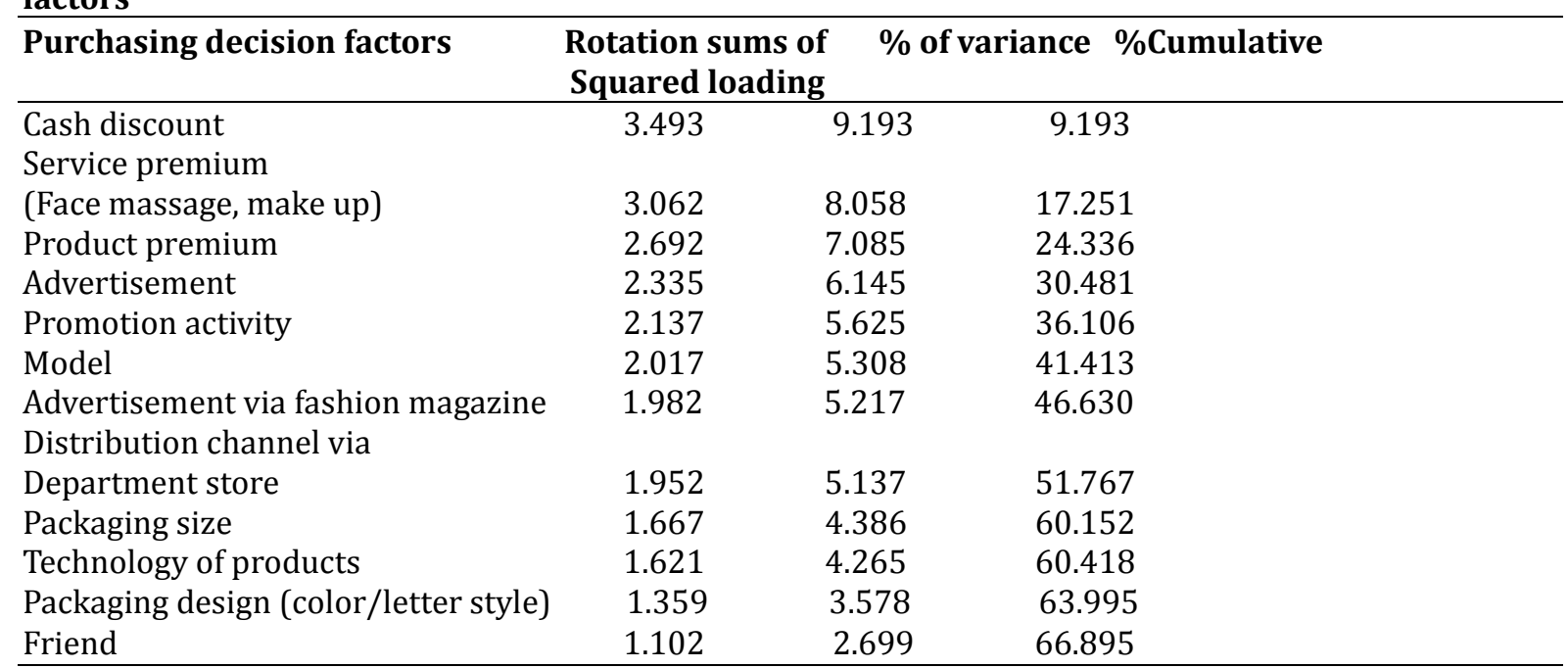




\section{Conclusion and Discussion}

\section{Marketing strategy of imported herbal cosmetic products}

- Products Strategy: The imported herbal cosmetic products are concerned with the odor, color, physical appearance of products and penetration characteristic of products. The strategy for promoting the imported herbal cosmetic products are an introduction of the products; advertising the products blend of potent herbs that can help effective skin care to healthy, revitalize skin and natural extract contains active ingredients with high technology manufacture the cosmetic product that perform a specific action to penetrate to the deep skin. The smooth odor and color of imported products are the important purchasing decision factors. Physical appearance of products; non greasy, non oily help absorbs quickly into skin and help smooth the skin surface texture.

- Packaging: Packaging design, color, size and shape, play a role in purchasing decisions. Packaging has to possess the strength to make eye-catching packaging as its helps to make the most window of opportunity in pristine conditions.

- Brand, logo/slogan: Brand as a way to facilitate their purchasing decision, the image of the brand has all the criteria value, quality reliability trust, intangible and deliver benefits to the consumers.

- Price Strategy: Price is heavily differentiated due to the branding then imported herbal cosmetic product offering more lower price by making smaller sizes of some products, such as $50 \mathrm{ml}$ and $30 \mathrm{ml}$ bottles of products, which is normally sold in $100 \mathrm{ml}$ bottles then smaller bottles are selling better than regular size one.

- Place Strategy: purchasing convenience from the Internet to virtual presence e.g. website, direct mail, social media enhance the brand's image. The site also uses Face book by constantly updating content photo, videos, information about events, YouTube, twitter as platforms to keep customers up to date on new episodes and development.

- Promotion Strategy: Advertisement, television advertisement

\section{Marketing strategy of Thai herbal cosmetic products}

- Product Strategy: Advertisement the products; Thai herbal cosmetic product have beneficial effect on the skin and works effectively to maintain the skins natural surface renewal cycle and acts to correct and treat the skins specific needs. The marketing strategy of Thai products by improving the quality of product, research and development of new products for launch to the market and create beauty packaging. New products launch attract the market's attention.

- Price Strategy: Cash discount is the best strategy to increase consumer's purchase motive of Thai products.

- Place Strategy: Department store is one best way to distribute products.

- Promotion Strategy: Integrated marketing communication for maintaining brand image. Distribution channel are direct sale with catalog, counter in department store, beauty showroom, television advertisement, radio advertisement, cabal advertisement, booth exhibition, build beauty school, website, face to face marketing and male beauty instructor.

Table 11: Comparative significant purchasing decision factors between Imported and Thai Herbal cosmetic products

\begin{tabular}{ll}
\hline Imported Herbal Cosmetic Products & \multicolumn{1}{c}{ Thai Herbal Cosmetic Products } \\
\hline Odor of products & Cash discount \\
Color of products & Service premium \\
& (Face massage, make up) \\
Physical appearance of products & Product premium \\
Brand & Advertising \\
Technology of products & Promotion activity \\
Penetration characteristic of products & Model \\
Logo /slogan & Advertisement via fashion magazine \\
Distribution channel via the Internet & Distribution channel via department store \\
Price (Cost) & Packaging size \\
Advertisement & Technology of products \\
Packaging & Packaging design (color/ letter style) \\
Television advertisement & Friends \\
\hline
\end{tabular}


The most important of purchasing decision factors of imported products is odor of product then manufacturers and marketers should produce the cosmetic to respond this customer's need. Other purchasing decision factors are sort from more important to least important decision factors as follow color, physical appearance of products, brand, and technology of products, penetration characteristic, and logo/slogan, distribution channel via internet, price, advertisement, packaging and television advertisement. The most important of purchasing decision factors of Thai products is cash discount then manufacturers and marketers should produce the cosmetic to respond this customer's need. Other purchasing decision factors are sort from more important to least important decision factors as follow; service premium(face massage, make up), product premium, advertising, promotion activity, model, advertisement via fashion magazine, distribution channel via department store, packaging size, technology of products, packaging design(color/ letter style) and friends. Production than Thai products but the imported products are more expensive than Thai production. Thai consumers were very satisfied with the bottle with pump packaging of imported products. Thai consumers say the convenient to purchase both products from department stores and direct sales. The marketing promotion of imported products is more interesting than Thai products. The marketing promotions are new product premium, promotion campaigns e.g. cash discount, gift premium, fortune, tarot horoscope, and make-up and massage workshop. Thai consumers satisfy with advertisement of both products; brochure, leaflet, beauty information from general magazine, fashion magazine, television and radio. The economic situation such as inflation situation is the major factor of purchasing decision. The average of cosmetic budget per purchase is 1,800 baht (about $\$ 50$ ) and Thai consumers purchase cosmetics in 2010(average) are eight purchases per year.

Conclusion of Quantitative Research: Imported and Thai Herbal cosmetic products have grown in popularity with consumers over the past ten years. Most of the products are formulated with the highest quality with natural active plants and certified natural ingredient to produce high performance natural skin care. The imported herbal cosmetic products were significantly concerned the factors of odor, color, physical appearance of products and product premium then manufactures and marketers should respond to the need of customers. The support marketing strategy of imported herbal cosmetic products are concerned in brand loyalty, technology of products, penetration characteristic logo/slogan, product value, advertisement, packaging, and television advertisement. The marketing strategy of Thai herbal cosmetic products are significantly concerned about cash discount, service premium (face massage, make up) and product premium. The support marketing strategy of Thai herbal cosmetic products are concerned in advertisement, promotion activity, model, fashion magazine advertisement, distribution channel in department store, packaging size of products, production technology, packaging design (color, letter style), friends are purchasing decision factors.

Discussion of Quantitative Research: Thai customers consume Thai herbal products because of they need to help Thai economics then Thai's manufacturers should increase the quality of products and respond to the customer's need by manufactures following Good Manufacturing Procedure(GMP); it is a production and testing practice that helps to guarantee the quality of products. The quality of product is an important factor because word of mouth is one of the strongest marketing tools. Price a cost of appreciation is an important purchasing decision factor. The most successful luxury campaigns are fully integrated with a larger strategy and align with the brand's value. The slogan is important for enhancing brand's image and upgrading the brand image. The campaigns and place of convenience to buy can be used to support all other touch points including events, exhibition, website, campaigns and customer service. Promotion through communication by offering special promotion events; coupons, sweepstakes, and on line advertising are the choice of the marketing channel. Co-marketing with sponsor for fashion show, wedding essentials magazine, free make up consulting is the choice for increased sales volume. A slogan is important for enhancing brand's image and upgrading the brand image. To joint venture together with local partner can increase the power of the capital investment.

Implementation: This thesis is the database to plan the Thai and Imported herbal cosmetic products marketing strategy in Thailand. Marketing strategies implementation is constrained by marketing strategies concepts. The products must be differentiated by products allowing consumer to perceive differences in characteristics, positioning, segmentation, targeting and image from competitors. The products have specific positioning by consumers receiving a brand differentiate relative to competitor. The company has a marketing research to provide company with information impact on 4Ps; product strategy, pricing strategy, place and distribution strategy and promotion strategy. Developmentation of the 
marketing strategy are analysis of past performance, understanding of competition to gain customers satisfaction and building customer trust. This thesis has the marketing strategy's database of Thai and the imported herbal cosmetic industry in Thailand.

\section{References}

Amor, I. \& Guilbert, F. (2009). Influences on free samples usage within the luxury cosmetic market. Direct Marketing an International Journal, 3, 67-82.

Arnum, P. (2004). Emerging markets critical to growth for cosmetic and personal care. ICIS Chemical Business America, 18, 266-267.

Cosmetic Herbal Sundies Business Plan. (2012). Retrieved June 5,2012 from http://www.bplans.co.uk/cosmetic_herbal_sundries_business_plan/market_

Cosmetic Products Market-Thailand. (2009). Retrieved April 14, 2009 from http://www.buyusa.gov/asianow/thcosmetic.html

Chi, H., Chien, H. \& Chiou, C. (2009). The effects of brand affect on female cosmetic users brand loyalty in Taiwan. The Journal of American Academy of Business, Cambridge, 14, 230-236.

Cynthia, C. \& Arnum, P. (2002). Raw Material Suppliers Roll out New Products for Cosmetic and Personal Care. ICIS Chemical Business Americas, 13, 6-7.

Ergin, E., Ozdemir, H. \& Parilti, N. (2005). Brand Loyalty in the Cosmetic Industry: A field study on Turkish women's brand loyalty among cosmetic product. Journal of Business \&Economics Research, 4, 5-16.

Estee Lauder joins L'Oreal and P\&G in lowering prices to boost sales. (2012). Retrieved April 24, 2012 from http://www.cosmeticdesign.com/Business-Financial/ Estee-Lauder-L-Oreal-and P-G

Jalalkamali, M. \& Nikbin, A. (2010). The effects of motivation on purchase decision. Interdisciplinary Journal of Contemporary Research in business, 2, 234-245.

Jui, Y., Mei-Liang, C. \& Yi-chieh, C. (2008). The Study of Direct Selling Management Strategies: An example of the Avon cosmetics company in Taiwan. Journal of International Management Studies, 2, 214227

Ministry of finance. (2009). Retrieved April14,2009 from http://www2.mof.go.th/

Pailin, J. \& Paul, B. (1995). Using information situations to guide marketing strategy. Journal of Consumer Marketing, 12, 19-27.

Rojanadilok, T. \& Bunchapattanasakda, C. (2011). Marketing Strategies of Imported Herbal Cosmetic in Thailand. Information Management and Business Review, 3, 217-221.

Sun, P. \& Hwang, I. (2005).The Impact of new product launch strategies on the reaction of competitors in the Taiwanese cosmetic industry. International Journal of Management, 22, 442-449

The market council (2012). Retrieve September 6, 2012 from http://the marketcouncil.comInternational-beauty-product-marketing-trend 